\title{
Toward pesticidovigilance
}

Can lessons from pharmaceutical monitoring help to improve pesticide regulation?

\author{
Alice M. Milner ${ }^{1^{*}}$ and Ian L. Boyd ${ }^{2}$ \\ ${ }^{1}$ Department of Geography, Royal Holloway, University of London, Egham, Surrey TW20 oEX, UK \\ ${ }^{2}$ School of Biology, College Gate, University of St Andrews, St Andrews, Fife KY16 9AJ, Scotland, UK \\ *Corresponding author: alice.milner@rhul.ac.uk

\section{Author accepted manuscript for paper published on $22^{\text {nd }}$ September 2017 Science | Volume 357 | Issue 6357 | Pages 1232-1234 | DOI: 10.1126/science.aan2683}

Agricultural pesticides are an important component of intensive agriculture and, therefore, of global food production. In the European Union, approximately 500 active substances used in pesticides are currently approved, including insecticides, fungicides, herbicides, and plant growth regulators. When used at industrial scales, pesticides can harm the environment (1), but there is a trade-off between this effect and the need to produce food. Recent uncertainties about the health and environmental effects of glyphosate herbicide and neonicotinoid insecticides underline the need for regulation to be sensitive to this trade-off $(2$, 3). Better regulation is needed to control how pesticides are used and affect the environment at a landscape scale.

Important insights into how pesticides can be better regulated come from the regulation and monitoring of pharmaceuticals. In particular, antibiotics provide some intriguing parallels with pesticides. Society depends on pesticides in a similar way to how it relies on antibiotics. Both have been manufactured and supplied to market demand with little care taken to consider whether this is sensible. Both are often used prophylactically or as therapies of first resort, when sparing use would be more appropriate. Both are vulnerable to loss of efficacy because of resistance in target organisms. And, in both cases, there are market failures in supply because of the costs of market entry (4-6). This cost is mainly driven by the need to sustain high standards of safety, including environmental safety in the case of pesticides. There is now a global effort to resolve the problem of loss of effective antibiotics. We suggest that more effective global governance of pesticides and their use is also needed.

Standard environmental toxicity tests used to license pesticides are performed on particular test species and have limited predictive power when chemicals are used widely. Diffuse environmental effects that arise from ecosystem connectivity at a landscape scale are hard to measure but may still be appreciable. There is a low level of trust in current toxicology testing regimes because they are unable to encompass the full range of toxic effects that could emerge 
when used at scale. This is resulting in precautionary regulation and the gradual withdrawal of key pesticides from the market (7). The withdrawal of pesticides will incentivize innovations, including changes to the crops grown, cultivation methods, and new types of pesticides. However, the abrupt withdrawal of pesticides may lead to the use of alternatives which can be just as problematic. Agricultural systems need time to adapt, and regulation can help to make the use of a pesticide more proportionate to the trade-off between costs and benefits.

How can this be achieved? Comparison with the regulation of pharmaceuticals may help to find an answer (see the table). The pharmaceutical and pesticide industries both seek bioactive chemicals with doseand species-dependent effects. However, governance and vigilance (continued surveillance for indicators of negative effects) of pharmaceuticals and pesticides differ widely once market authorization has been granted.

The overarching principle for pharmaceutical governance is to ensure that medicines are effective, safe, and marketed on the basis of need. Regulation, under the global governance of the World Health Organization (WHO), aims to balance encouraging the development and appropriate use of new medicines and preventing the use of ineffective or harmful ones.

By contrast, there is no global governance for pesticides, and national pesticide standards vary around the world $(8,9)$. International harmonization of pesticide registration procedures is being attempted through the OECD Agricultural Pesticide Programme. Member countries are encouraged to harmonize methods to assess, report, and reduce the risks from pesticides. The United Nations (UN) Food and Agriculture Organization (FAO) International Code of Conduct on Pesticide Management, which was introduced in 1985 and revised most recently in 2014, sets voluntary standards for the management of pesticides in national legislation (10). However, implementation varies greatly between countries (11, 12). In most developed countries, approval of a substance requires an extensive dossier of evidence, but developing countries often lack the expertise to assess this evidence and have lower standards of implementation and enforcement $(8,12)$.

Pharmaceuticals that pass preclinical testing for safety and efficacy undergo three phases of trials (Phases I to III) with increasing patient numbers. These trials are designed to test effectiveness, determine safety, and identify side effects before marketing approval is sought. A fourth phase, Phase IV, begins once a product has been licensed and involves long-term safety monitoring of the product to reveal unexpected untoward effects when used at large scale. This long-term monitoring termed pharmacovigilance - involves the collection, detection, assessment, monitoring, and prevention of adverse effects of pharmaceutical products. It continues throughout the lifetime of each 
product, building a well-developed safety database for that product. Pharmacovigilance reporting systems such as the Yellow Card System (United Kingdom), EudraVigilance (European Union), the FDA Adverse Event Reporting System (United States), and VigiBase (global) are linked to the WHO Programme for International Drug Monitoring.

For pesticides, the process of substance discovery and early testing is similar. There are no defined phases equivalent to the phases I to III used for medicines, but a similar process tests for effectiveness, toxicology, fate, and behaviour in the environment using a combination of laboratory (in vitro and in vivo) and field trials. If approved by the regulatory authority, the product can be used in accordance with the label for the duration of the license (typically 10 to 15 years in the European Union and 15 years in the United States).

However, there is no equivalent postmarketing mechanism to pharmacovigilance and no equivalent of Phase IV. Some post-license vigilance is present for protecting human health from the effects of pesticides. Food is monitored for maximum residue levels (MRLs) to help protect human health from the effects of consuming pesticides, but international MRLs vary widely. The Codex Alimentarius Commission sets nonbinding MRLs that can be adopted by countries with no agreedupon MRLs, but there is no global harmonization of levels. This could mean that foods exceeding MRLs in one country can be exported to countries with inadequate sampling or lower standards (8). Pharmacovigilance on the scale that is required for medicines does not exist to assess the effects of pesticides in the environment. The FAO recommends that countries report pesticide use, but this reporting normally only provides information about the total amount of any pesticide used annually, the total area of land treated with pesticides, and the range of crops treated. In countries without dedicated monitoring, pesticide sales statistics are used as a less accurate proxy. Reporting systems for incidents involving spills, livestock or wild animal deaths, or other effects of pesticide use are also lacking in many countries $(12,13)$. Regulation in the European Union and the United States requires that pesticide authorization holders submit new information on potentially dangerous effects of a pesticide on human or animal health, ground water, or the environment, but it is often not clear what they should be measuring and reporting; the onus is on the user to make a judgment about what is worth reporting, and compliance is rarely enforced effectively.

In some countries, such as the United Kingdom, other European Union member states, and the United States, all reported pesticide incidents involving people, wildlife, or the environment are investigated, but there is no equivalent to the Yellow Card, EudraVigilance, or VigiBase systems to monitor the environmental effects of pesticides during normal use. There is also no estimate of the number of incidents that 
go unreported and that are therefore not investigated. Monitoring and preventing misuse, accidents, and unintended effects of pesticides requires investment in organizational design for information collection and processing, which is absent in most countries.

The United Kingdom has one of the most developed regulatory and monitoring systems for pesticides. Yet, it has no systematic monitoring of pesticide residues in the environment, and no equivalent to MRL in foods exists for the environment. There is no consideration of safe pesticide limits at landscape scales. For example, statistics about the use of neonicotinoids in the United Kingdom suggest that the landscape-scale dose increased by a factor of four between 2000 and 2014 (14). Without knowledge of safe environmental limits, the total pesticides used - and therefore the total environmental dose - is governed by market demand rather than by a limit on what the environment can endure. There is little information about where, when, and why pesticides have been used, making it very difficult to quantify potential environmental effects.

An essential step for pesticide regulation in the future is to develop an equivalent to pharmacovigilance - perhaps called pesticidovigilance. Such a system would place responsibility for monitoring the use and effects of these chemicals on manufacturers and growers by applying preregistered designs for how data should be collected. It would improve decisions concerning approved use and would avoid sole reliance on ad hoc studies and sparse data. New methods of precision farming provide opportunities for new data flows. This would also address issues of environmental justice by placing the responsibility for active management of pesticide dosing on those who benefit directly and who have the capacity to adapt and innovate. It would be a foundation for defining best practice, allowing the level of precaution applied in regulation to be scaled to the level of knowledge about the effects of the pesticides. Such a system would promote genuinely risk-based pesticide use that would make the trade-offs between the environmental costs and food production more explicit. In specific circumstances where there are strong reasons for protecting a vital crop, a risk-based system could even allow some chemicals currently banned under the present systems of regulation to be used.

The better alignment of pesticide use with this kind of best practice is in everybody's interest. It has the potential to increase trust and to sustain the use of important chemical technologies. The current assumption underlying pesticide regulation - that chemicals that pass a battery of tests in the laboratory or in field trials are environmentally benign when they are used at industrial scales - is false. Future regulation to deal with this issue may have to vary regionally because of differing costbenefit analyses, but the effects of dosing whole landscapes with chemicals have been largely ignored by regulatory systems. This can and should be changed. 


\section{Table: How pharmaceuticals and pesticides are regulated}

During early stages of discovery and testing, pharmaceuticals and pesticides are regulated in a similar way, but in the later stages and after approval, pharmaceuticals are monitored far more effectively.

\section{Pharmaceuticals}

Pesticides

Substance discovery and development
Search for and synthesize molecules; perform biological tests and screening to determine biological activity; determine commercial prospects (e.g., potential for patents).

\section{Preclinical and pre-field testing}

Conduct safety, efficacy, and toxicological tests using in vitro and in vivo laboratory trials and computer modelling.

\begin{tabular}{|c|c|c|}
\hline $\begin{array}{l}\text { Clinical and field } \\
\text { testing }\end{array}$ & $\begin{array}{l}\text { Test effectiveness, determine } \\
\text { safety, and identify side effects } \\
\text { using three levels of trials [phase I } \\
\text { (first in human), II, and III] with } \\
\text { increasing patient numbers. }\end{array}$ & $\begin{array}{l}\text { Test effectiveness, toxicology, } \\
\text { fate, and behaviour in the } \\
\text { environment using laboratory and } \\
\text { field trials. No equivalent to the } \\
\text { phased trials used in } \\
\text { pharmaceutical testing. }\end{array}$ \\
\hline $\begin{array}{l}\text { Registration and } \\
\text { approval }\end{array}$ & \multicolumn{2}{|c|}{$\begin{array}{l}\text { Submit development study results on efficacy, effectiveness, safety, } \\
\text { toxicology, fate, and behaviour to regulatory body for license approval. }\end{array}$} \\
\hline $\begin{array}{l}\text { Post-approval } \\
\text { marketing, use, } \\
\text { and monitoring }\end{array}$ & $\begin{array}{l}\text { Once licensed, the substance can } \\
\text { be used in accordance with the } \\
\text { product label. Long-term } \\
\text { monitoring starts (phase IV) to } \\
\text { determine unexpected effects in } \\
\text { different categories of people and } \\
\text { the population more generally } \\
\text { (using national and global } \\
\text { reporting systems and } \\
\text { pharmacovigilance regulations). }\end{array}$ & $\begin{array}{l}\text { Once licensed, the substance can } \\
\text { be used in accordance with the } \\
\text { product label (MRL monitoring } \\
\text { checks compliance with product } \\
\text { label to protect human health). Ad } \\
\text { hoc reporting of incidents or } \\
\text { effects. No post- approval or long- } \\
\text { term monitoring of effects and no } \\
\text { equivalent to pharmacovigilance. }\end{array}$ \\
\hline
\end{tabular}




\section{References and Acknowledgements}

1. H.-R. Köhler, R. Triebskorn, Science 341, 759 (2013).

2. J. P. Myers et al., Environ. Health 15, 19 (2016).

3. F. Sánchez-Bayo, Science 346, 806 (2014).

4. M.Lechenet, F.Dessaint, G.Py, D.Makowski, N.Munier-Jolain, Nat. Plants 3, 17008 (2017).

5. B. Borel, Nature 543, 302 (2017).

6. Phillips McDougall, "The cost of new agrochemical product discovery, development and registration in 1995, 2000, 2005-8 and 2010 to 2014" (CropLife International, CropLife America and European Crop Protection Association, 2016); http://www.croplifeamerica.org/wpcontent/uploads/2016/04/Phillips-McDougall-Final-Report_4.6.16.pdf

7. European Food Safety Authority (EFSA), Eur. Food Safety Authority J. 11, 3066 (2013).

8. C. E. Handford, C. T. Elliott, K. Campbell, Integr. Environ. Assess. Manag. 11, 525 (2015).

9. United Nations Human Rights Council, "Report of the Special Rapporteur on the right to food"A/HRC/34/48 (2017); www.ohchr.org/EN/Issues/Food/Pages/Annual.aspx

10. Food and Agriculture Organization of the United Nations and World Health Organization (FAO and WHO), "The International Code of Conduct on Pesticide Management" (2014); www.fao.org/fileadmin/templates/agphome/documents/Pests_Pesticides/Code/CODE_2014Se p_ENG.pdf

11. L. V. Dicks et al., Science 354, 975 (2016).

12. G. Matthews et al., Environ. Health Perspect. 119, 1517 (2011).

13. European Commission, "A common methodology for the collection of pesticide usage statistics within agriculture and horticulture" (Eurostat Methodologies and Working Papers, European Communities, 2008); http://ec.europa.eu/eurostat/ramon/statmanuals/files/KS-RA-08- 010EN.pdf

14. Fera. PUS STAT: Pesticide Usage Surveys (2015); https://secure.fera.defra.gov.uk/pusstats/surveys/index.cfm

A.M.M. acknowledges funding from the Natural Environment Research Council (NERC) and UK Government Department for Environment, Food, and Rural Affairs (Defra) for a secondment to Defra (NE/Loo8599/2). I.L.B. is chief scientific adviser at UK Defra. The views in this paper are the authors' own. 